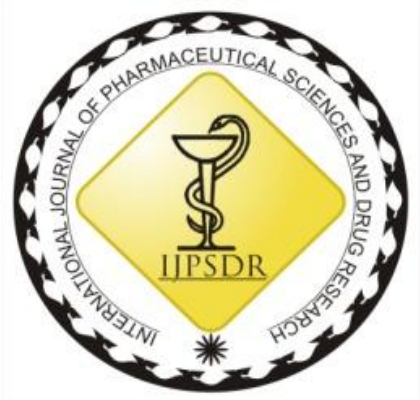

ISSN: 0975-248X

RESEARCH ARTICLE CODEN (USA): IJPSPP

$(\mathrm{cc})$ EY-NC-SA

\title{
Isolation, Identification and Characterization of Degradation Impurity of Atorvastatin in Fixed Dose Combination of Atorvastatin and Ezetimibe
}

\author{
Rajesh Desai ${ }^{1}{ }^{*}$, Suresh Koradia ${ }^{2}$ \\ ${ }^{1}$ School of Science, RK University, Rajkot, Gujarat, India \\ ${ }^{2}$ Shree M. \& N. Virani Science College, Rajkot, Gujarat, India
}

Copyright (C) 2019 Rajesh Desai et al. This is an open access article distributed under the terms of the Creative Commons AttributionNonCommercial-ShareAlike 4.0 International License which allows others to remix, tweak, and build upon the work non-commercially, as long as the author is credited and the new creations are licensed under the identical terms.

\begin{abstract}
The objective of this study is to isolation and characterization of unknown degradation product of Atorvastatin calcium in combination formulation product with Ezetimibe by using modern techniques of separation and characterization. An unknown impurity is generating during a forced degradation study of Atorvastatin and Ezetimibe fixed-dose combination tablets. By using the gradient reversed-phase high-pressure liquid chromatographic method, unknown degradation impurity was detected and quantified in the range of $0.05 \%$ to $0.2 \%$ of Atorvastatin. The impurity was enriched by extreme oxidation degradation of Atorvastatin and isolated through preparative HPLC. The structure of the impurity was characterized by mass and NMR spectrum.
\end{abstract}

Keywords: Atorvastatin calcium, Ezetimibe, HPLC, Mass, NMR, Degradation.

DOI: 10.25004/IJPSDR.2019.110506

Int. J. Pharm. Sci. Drug Res. 2019; 11(5): 187-193

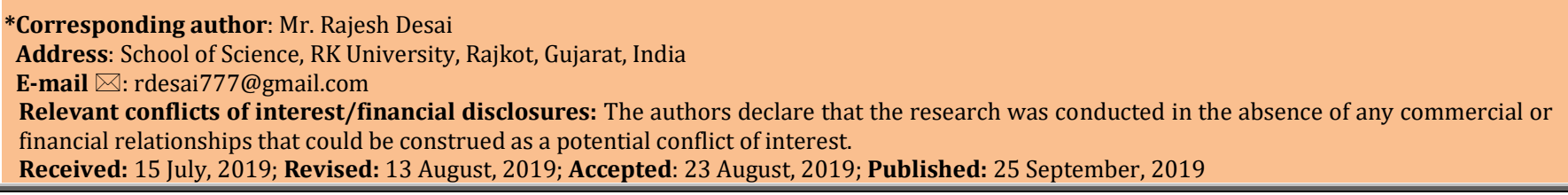

\section{INTRODUCTION}

Hypertension is the most common disease worldwide; this is a major risk factor for cardiovascular disease. Most of the population is suffering from higher blood pressure and obesity with a high level of bad cholesterol (i.e. LDL, triglycerides). A fixed-dose combination product of Atorvastatin and Ezetimibe Tablets was used as a hypertensive drug and its helps to reduce the LDL cholesterol level in blood. High risk of the heart disease can be reduce by decreasing the LDL cholesterol and triglyceride level by using this combination product and it helps to reduce the risk of coronary heart disease and similar critical conditions. [1]
Chemical name of Atorvastatin is $(\beta R, \delta R)-2-(4-$ Fluorophenyl)- $\beta, \quad \delta$-dihydroxy-5-(1-methylethyl)-3phenyl-4-[(phenylamino) carbonyl]-1H-pyrrole-1heptanoic acid calcium salt trihydrate. [2] Appearance of Atorvastatin calcium is a white crystalline powder. The chemical and physical property of the compound shows it is soluble in dimethyl sulfoxide, practically insoluble in water, alcohol, and dichloromethane. Molecular formula is $\mathrm{C}_{66} \mathrm{H}_{68} \mathrm{CaF}_{2} \mathrm{~N}_{4} \mathrm{O}_{10} .3 \mathrm{H}_{2} \mathrm{O}$. [2] Appearance of Ezetimibe is a white, crystalline powder. The chemical and physical property of the compound is shows it is soluble in alcohol and acetone. Ezetimibe is practically insoluble in water. [3] 
Combination of the product is available in the market and few methods for determination of impurity of the combination product by high-pressure liquid chromatography are available. Impurity profiling of the combination product is critical to its safety assessment and formulation process. ${ }^{[4-13]}$ To separate all possible degradation impurities a specific and selective reverse phase chromatographic method was developed and force degradation study was planned. Several degradation products were generated during the degradation study of combination product which is known and reported. Some of the unknown degradations are not observed increased potential. In oxidative degradation with hasher condition, one impurity was increased which can be a hazard with regards to toxicity issue. The present study provides isolation, characterization, and identification of the unknown degradation product which is related to Atorvastatin. The unknown impurity was isolated by preparative HPLC and characterized by LCMS and NMR techniques. Literature survey shows an analytical method for related impurities by HPLC for Atorvastatin [14-18], Ezetimibe [19-21] and for combination product of Atorvastatin and Ezetimibe is available to determine related impurities of Atorvastatin and Ezetimibe.

The presence study is important for identify potential degradation impurity in current marketed product and can control this impurity in formulation as a good product life cycle approach. Also, it will help in new drug development activity to save overall time for identification and characterization of degradation products. The present study provides the isolation, characterization, and identification of the unknown degradation product of the Atorvastatin, which is characterized by LCMS and NMR spectrums.

\section{MATERIALS AND METHODS}

\section{Material and reagents}

The raw material of Atorvastatin calcium trihydrate API, Ezetimibe API, Atorvastatin and Ezetimibe combination tablets ware received from a well-known pharmaceutical company.

\section{Solution preparation}

\section{Mobile phase A}

$20 \mathrm{mM}$ Ammonium Acetate buffer $\mathrm{pH} \quad 5.0$ Approximately weighed and transferred $3.08 \mathrm{~g}$ ammonium acetate into $1000 \mathrm{ml}$ water and dissolved it. Adjust $\mathrm{pH}$ of 5.0 with diluted glacial acetic acid.

\section{Mobile phase B}

The mobile phase was prepared by proper mixing of acetonitrile $(950 \mathrm{ml})$ and THF (Tetrahydrofuran) (50 $\mathrm{ml})$.

\section{Diluent preparation}

The diluent was prepared by proper mixing of water $(200 \mathrm{ml})$ and acetonitrile $(800 \mathrm{ml})$.

Sample preparation for forced degradation study

A 10 tablets of Atorvastatin and Ezetimibe crushed into a fine powder and transferred into $100 \mathrm{ml}$ volumetric flask, added $20 \mathrm{ml}$ of diluent and sonicated for 30 minutes. $5 \mathrm{ml} \mathrm{30 \%} \mathrm{H} 2 \mathrm{O} 2$ solution and $2 \mathrm{ml}$ of $1 \mathrm{~N}$ $\mathrm{NaOH}$ solution was added and kept on room temperature for 7 days. After 7 days $50 \mathrm{ml}$ diluent was added in a volumetric flask and sonicated for 15 minutes. Cooled to room temperature and made volume up to the mark. Filtrate the sample through $0.45 \mu$ PVDF filter and analyzed in HPLC system.

High-performance liquid chromatography (HPLC analytical)

A Waters HPLC system with a quaternary pump, photo-diode array detector, and auto-sampler has been used for analysis. A reversed-phase liquid chromatography gradient method used to perform a forced degradation study of related substances method for Atorvastatin and Ezetimibe combination tablets. A YMC pack ODS-AQ, $250 \times 4.6 \mathrm{~mm}, 3 \mu \mathrm{m}$ column was used for analysis with a flow rate of $0.6 \mathrm{ml} /$ minutes. The analyte peaks were monitored and detection wavelength $244 \mathrm{~nm}$. A mixture of $20 \mathrm{mM}$ acetate buffer pH 4.5 and acetonitrile in the ratio of $70: 30 \% \mathrm{v} / \mathrm{v}$ was used as mobile phase A. Prepared $20 \mathrm{mM}$ acetate buffer $\mathrm{pH} 4.50 \pm 0.05$ and mixed with acetonitrile in the ratio of $350: 650 \mathrm{v} / \mathrm{v}$ and used as a mobile phase B. The mobile phase gradient was started at $05 \%$ of $\mathrm{B}$ up to 10.00 minutes and increased to $15 \%$ B within 10 minutes then increased to $50 \%$ of B within 10 minutes then increased up to $80 \%$ within 20 minutes. The injection volume was $20 \mu \mathrm{l}$. Diluent prepared by proper mixing of water and acetonitrile in the ratio of $20: 80 \%$ $\mathrm{v} / \mathrm{v}$.

\section{High-performance liquid chromatography} (Preparative HPLC)

Preparative HPLC is the technique which is used for isolation and purification of the compound. Shimadzu LC10 purification system was used to get good recovery with pure compund, with PDA detector and the flow rate is $5 \mathrm{ml} / \mathrm{min}$ with. An ODS-C18, $250 \mathrm{~mm} \times$ $21.2 \mathrm{~mm} \times 10 \mu \mathrm{m}$ reverse phase silica column was employed for the separation unknown impurity. The mobile phase used for the separation was $20 \mathrm{mM}$ ammonium acetate buffer as a mobile phase $\mathrm{A}$ and acetonitrile as mobile phase B, with the detection of 244 $\mathrm{nm}$. The mobile phase gradient was started at $25 \%$ of $\mathrm{B}$ and increased to $65 \%$ B within 80 minutes then increased to $90 \%$ of $B$ within 3 minutes.

\section{MASS spectroscopy (LC-MS/MS)}

The analysis was conduct in positive ionization mode with an electrospray interface in the range of 100-550 $\mathrm{m} / \mathrm{z}$. The parameters for the capillary and Rf voltage were $80 \mathrm{~V}$ with nebulizer gas air at a pressure of $35 \mathrm{psi}$ and curtain gas as nitrogen at a pressure of $10 \mathrm{psi}$.

The mass compatible method was developed to identify the unknown impurity of Atorvastatin. An YMC pack ODS, $250 \times 4.6 \mathrm{~mm}, 5 \mu \mathrm{m}$ column was used for analysis with a flow rate of $0.9 \mathrm{ml} /$ minutes. The analyte peaks were monitored and detection wavelength $244 \mathrm{~nm}$. $20 \mathrm{mM}$ acetate buffer $\mathrm{pH} 5.0$ was used as mobile phase A. Mobile phase prepared by 
Rajesh Desai et al. / Isolation, Identification and Characterization of Degradation Impurity of Atorvastatin.

proper mixing of acetonitrile and THF (tetrahydrofuran) in the ratio of $95: 5 \% \mathrm{v} / \mathrm{v}$. The gradient was started at $25 \%$ of $\mathrm{B}$ and increased to $65 \% \mathrm{~B}$ within 80 minutes then increased to $90 \%$ of B within 3 minutes. The injection volume was $10 \mu 1$. A mixture of water and acetonitrile in the ratio of $20: 80 \% \mathrm{v} / \mathrm{v}$ was used as a diluent.

\section{NMR Spectroscopy}

NMR spectra were obtained from a Bruker spectrometer using tetramethylsilane (TMS) as an internal standard in MeOD. Chemical shifts were in ppm concerning TMS. Coupling constants were in $\mathrm{Hz}$.

\section{RESULTS AND DISCUSSION}

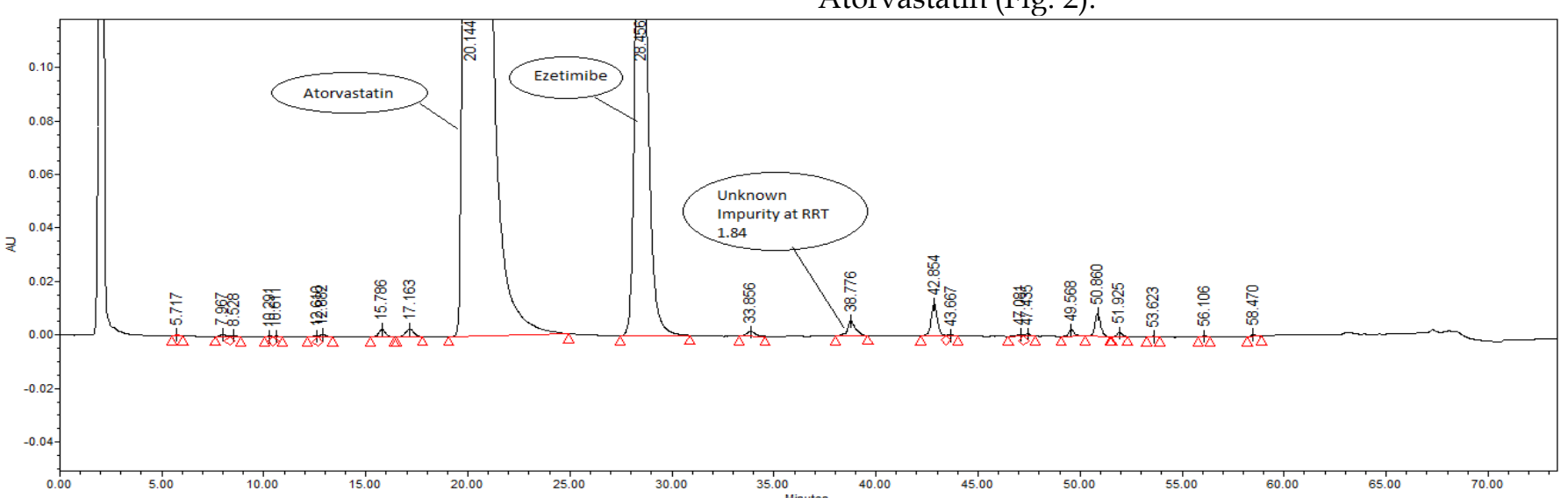

Fig. 1: Oxidative stress sample of Atorvastatin and Ezetimibe Tablets analyzed in HPLC system (Unknown degradation at eluted at relative retention time 1.84)

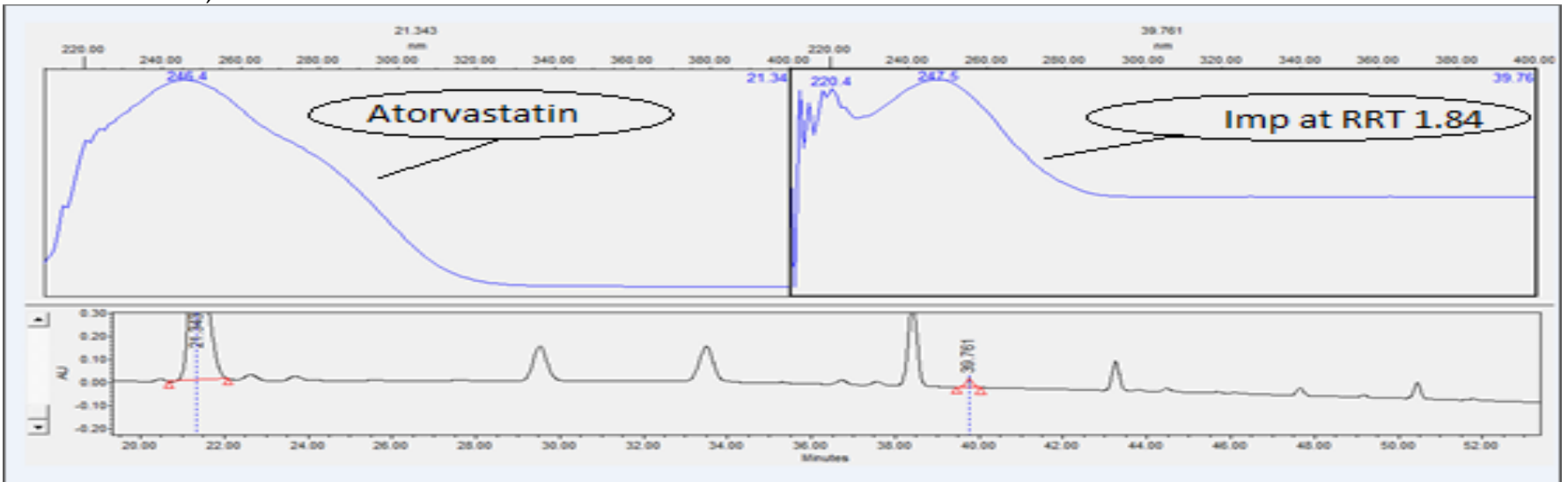

Fig. 2: UV spectrum of Atorvastatin and unknown impurity at RRT-1.84

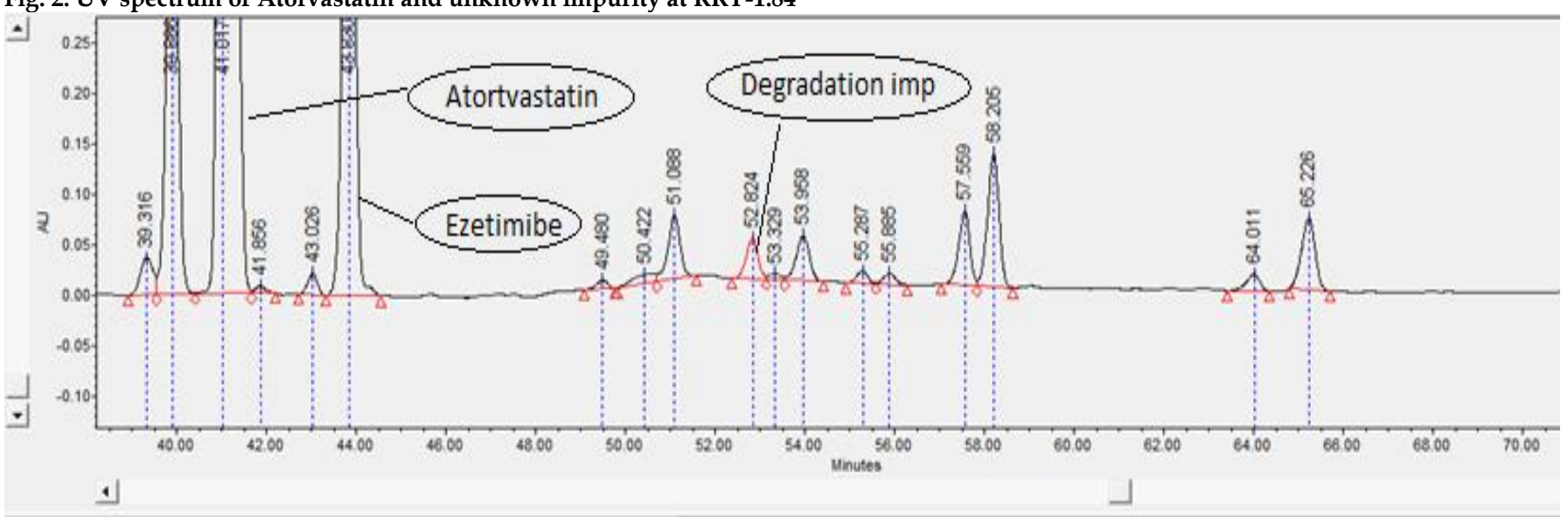

Fig. 3: Chromatogram of oxidative degradation sample in mass compatible HPLC method.
During the forced degradation study of Atorvastatin and Ezetimibe tables in the presence of oxidative agent such as hydrogen peroxide in basic condition, degradation impurity was generated. The reversedphase HPLC method for related substances test was developed for Atorvastatin and Ezetimibe tablets and validated as per ICH. The sample was stressed in oxidative condition and analyzed in a validated HPLC method for related substances of Atorvastatin and Ezetimibe Tablets. In HPLC chromatogram degradation impurity was observed at relative retention time 1.84 (Fig. 1). Based on the UV spectrum of unknown peak at RRT-1.84, it was concluded that the peak of unknown impurity at RRT-1.84 is a degradation product of Atorvastatin (Fig. 2). 
Rajesh Desai et al. / Isolation, Identification and Characterization of Degradation Impurity of Atorvastatin.

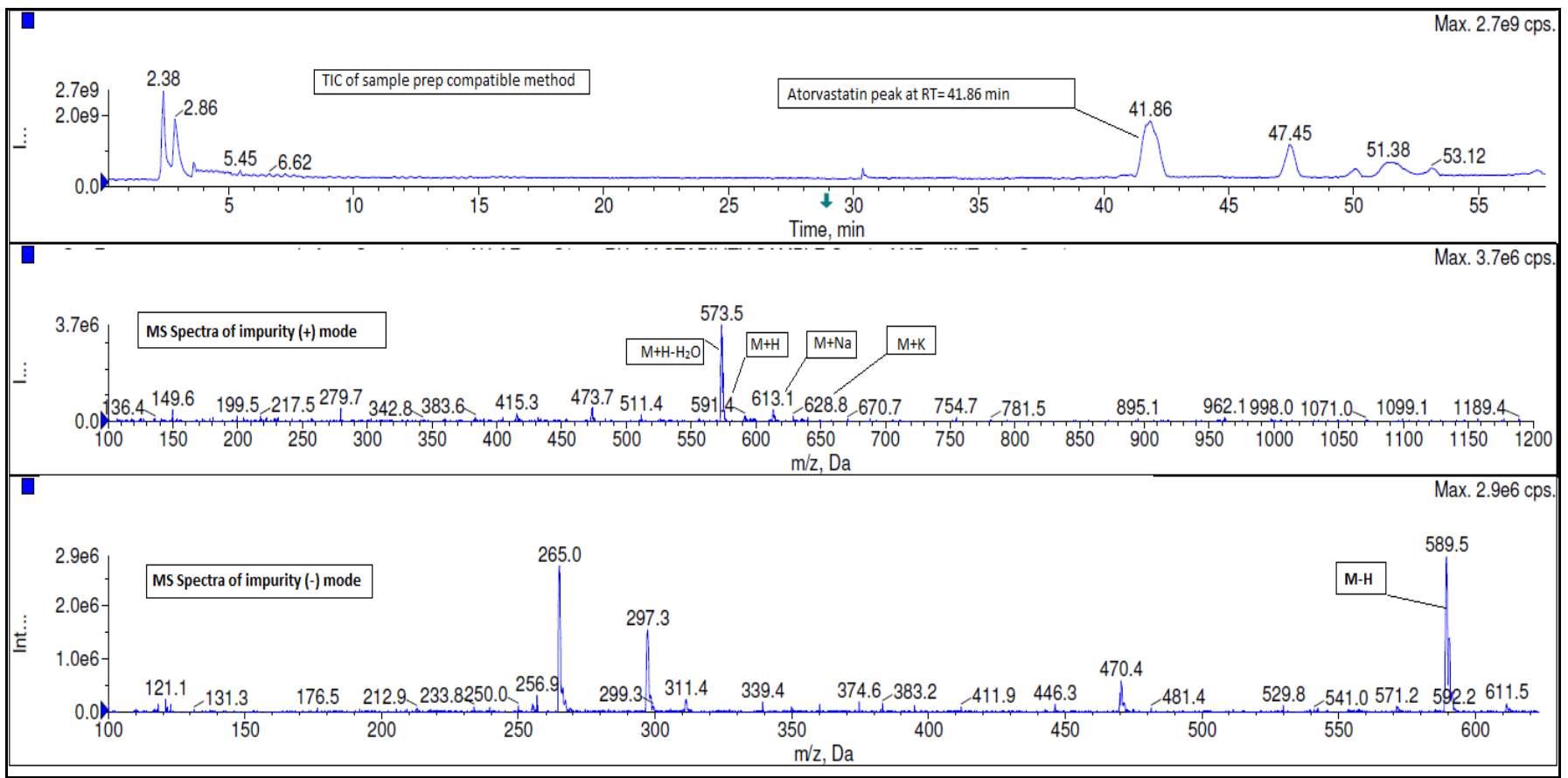

Fig. 4: LCMS/MS spectrum of degradation sample.

The oxidative degradation sample of Atorvastatin and Ezetimibe tablets was injected in the system to mass compatible HPLC method and the peak of interest eluting at 53.824 minutes (Fig. 3).

To identify the unknown impurity generated in Atorvastatin and Ezetimibe tables, the sample was injected in the LCMS/MS system to ascertain the unknown peak of interest eluting at retention time 52.824 (RRT-1.29) using the same chromatographic condition (Fig. 4).

The molecular ion peak of unknown impurity corresponding to $\mathrm{RRT}=1.29$ was deduced to be $\mathrm{m} / \mathrm{z}=$ 589.5 in negative mode and $\mathrm{m} / \mathrm{z}=591.4$ in positive mode.

The oxidative degradation of atorvastatin forms endoperoxide from pyrrole ring. MSMS fragmentation of the Atorvastatin shows the probable degradation (Fig. 6). Further, this impurity also showed loss of water molecule $\mathrm{M}-18=573.5, \mathrm{M}+\mathrm{Na}=\mathrm{m} / \mathrm{z}=613.1$ and $\mathrm{M}+\mathrm{K}=\mathrm{m} / \mathrm{z}=628.8$ corresponding to sodium and potassium ion adducts respectively. The most intense peak of 573.5 if the formation of the cyclic derivative of Atorvastatin. Daughter ion spectral data is also shown in Fig. 4 which confirms many fragments. Its details are shown in Fig. 5. Three common cleavage Sites are depicted which are common fragments of unknown impurity with atorvastatin (Table 1).

Table 1: Fragment mass from the spectral study of degradation impurity of atorvastatin.

\begin{tabular}{cccc}
\hline $\begin{array}{c}\text { Fragment mass of } \\
\text { unknown impurity }\end{array}$ & 375.17amu & 120.04amu & $480.21 \mathrm{amu}$ \\
$\begin{array}{c}\text { Fragment mass of } \\
\text { Atorvastatin }\end{array}$ & 438.21amu & 397.17amu & $\begin{array}{l}361.17 \mathrm{and} \\
447.21 \mathrm{amu}\end{array}$ \\
\hline
\end{tabular}

Probable structure of the impurity was derived by LCMS/MS fragmentation and to confirm the structure of the degradation impurity, the impurity was isolated by preparative HPLC. The chromatogram and spectra are shown to isolate the degradation compound, impurity was enriched and reparative HPLC method was developed. The impurity was isolated by preparative HPLC techniques. Approximate $9.070 \mathrm{mg}$ material was isolated and used for further characterization study.

Mass and NMR of the isolated material were done to confirm the structure of impurity.

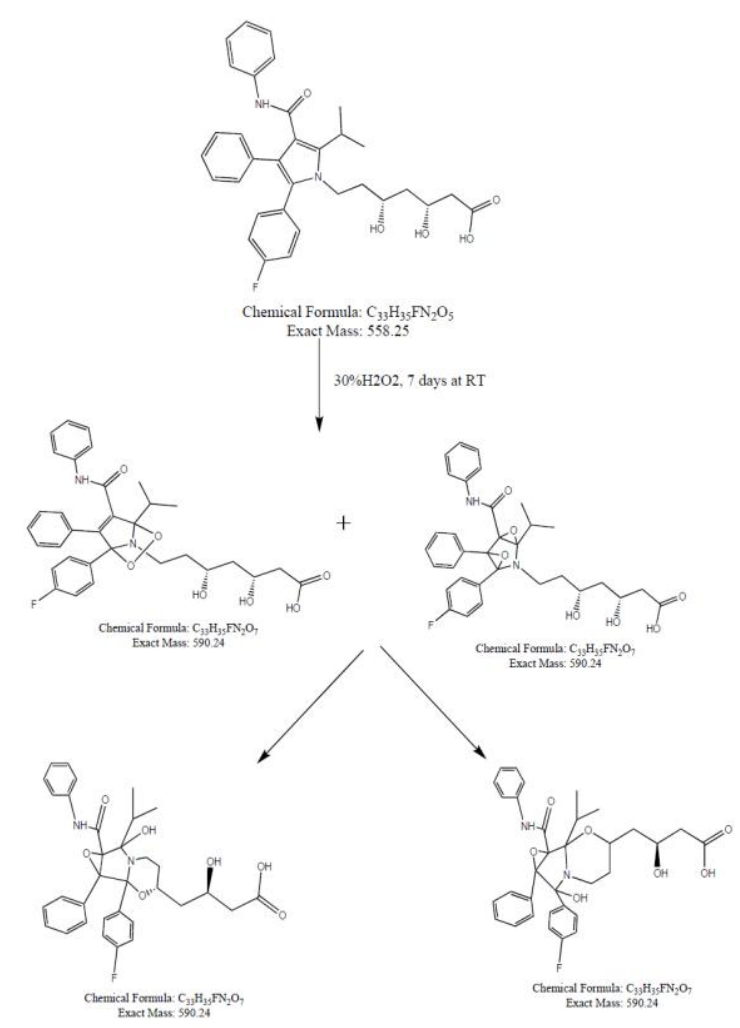

Scheme 1: Possible oxidative degradation of atorvastatin 


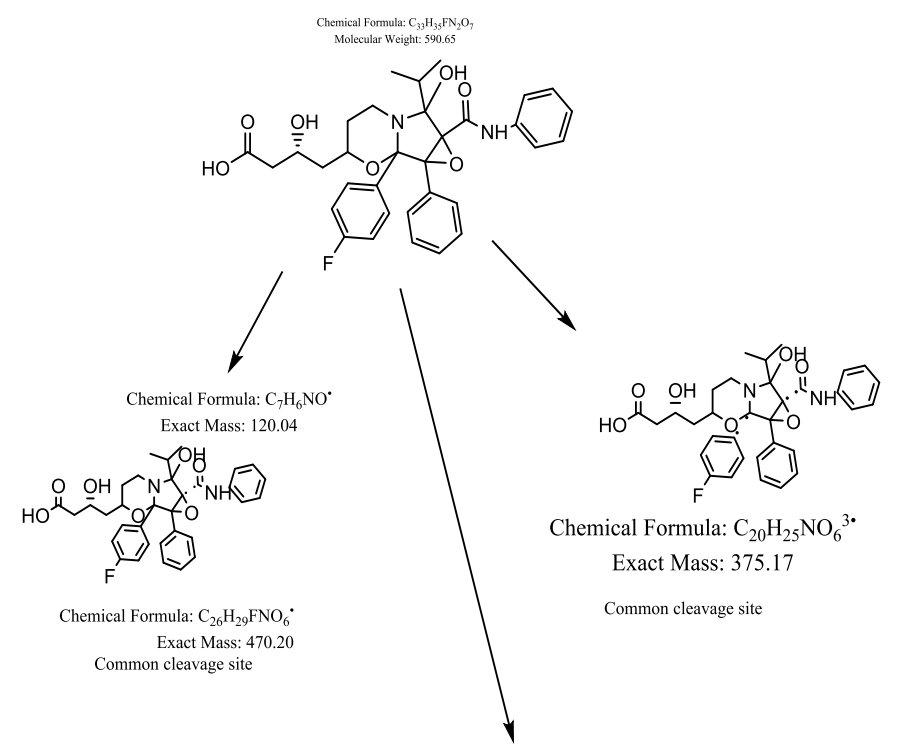

similar pattern was observed. Molecular ion peak is clearly visible $\mathrm{m} / \mathrm{z}=589.4$ in MS spectra.
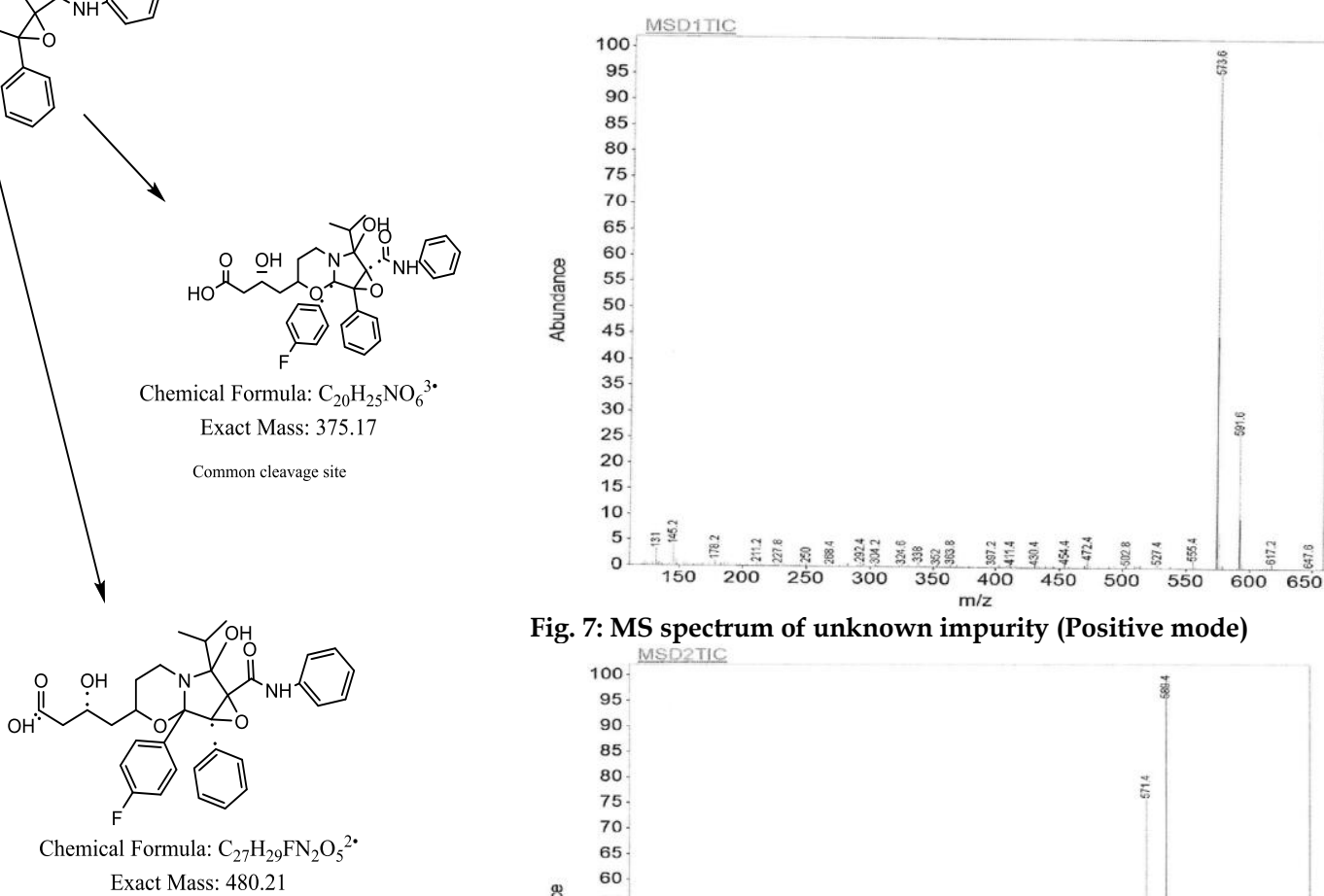

Common cleavage site

Fig. 5: MSMS fragmentation of unknown impurity at RRT-1.29 Chemical Formula: $\mathrm{C}_{33} \mathrm{H}_{35} \mathrm{FN}_{2} \mathrm{O}_{5}$ Molecular Weight: 558.65
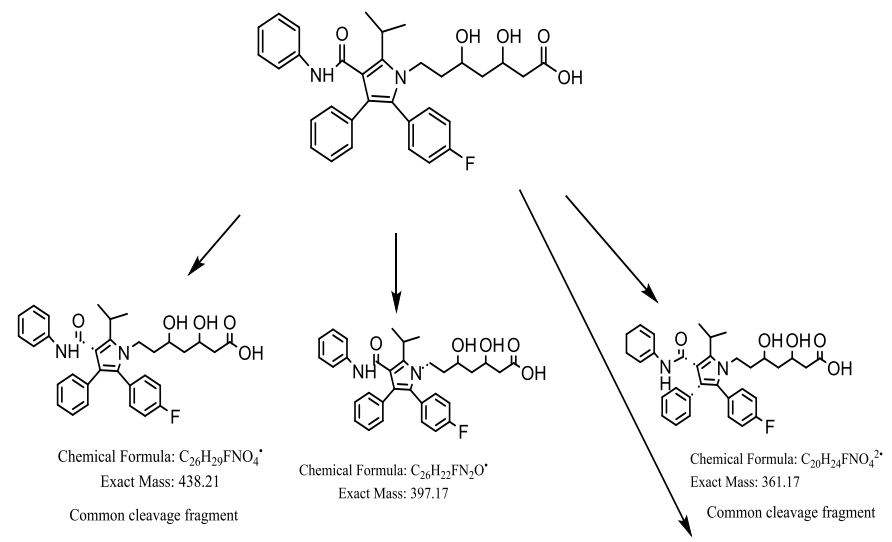

Fig. 7: MS spectrum of unknown impurity (Positive mode)

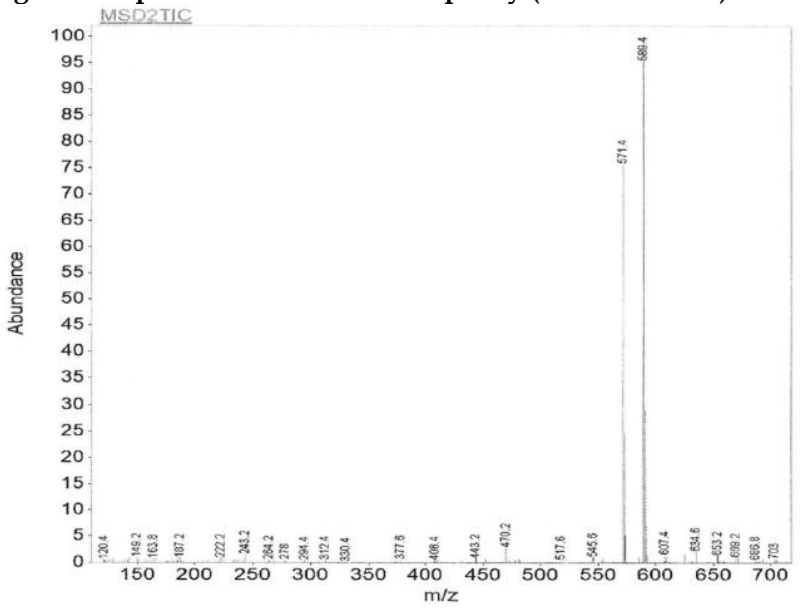

Fig. 8: MS spectrum of unknown impurity (Negative mode)

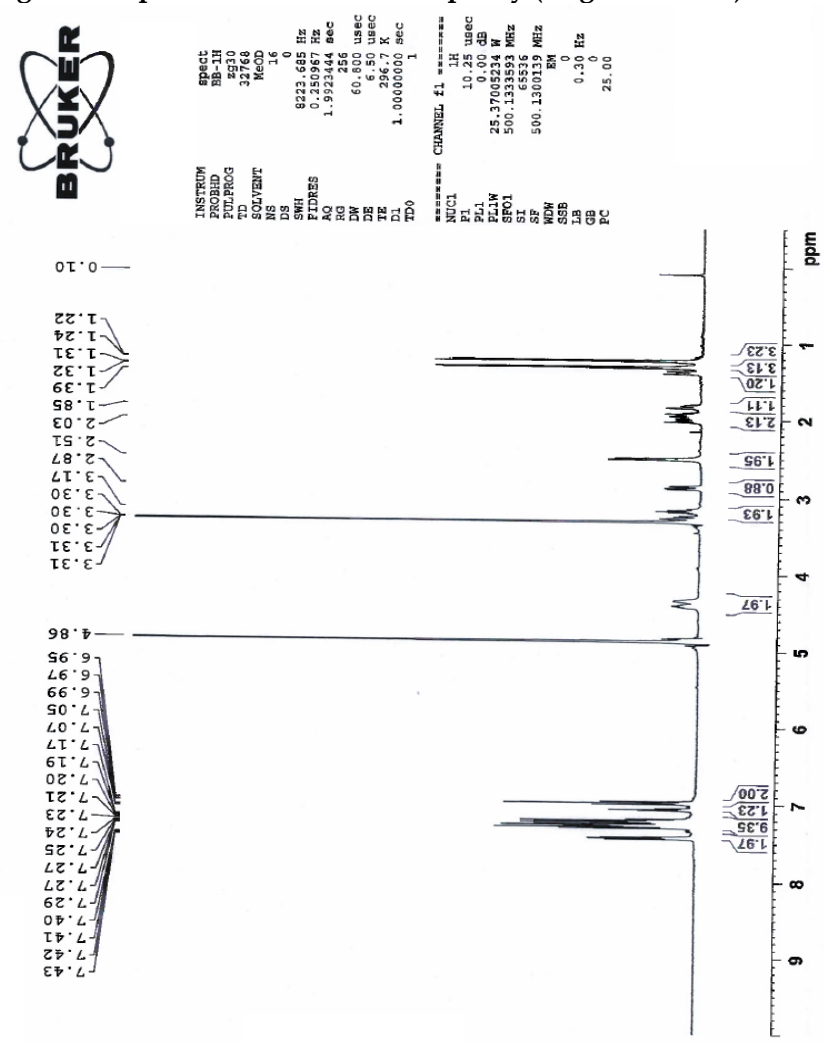

Fig. 9: ${ }^{1} \mathrm{H}$ NMR spectrum of unknown impurity temperature and voltages applied leading to greater intensity of $\mathrm{m} / \mathrm{z}=$ 573.4. In negative ion mode, $\mathrm{a}$ 
1H NMR spectrum analyzed in MeOD shows signals as mentioned below table,

\section{Table 2: NMR shif}

\begin{tabular}{ccc}
\hline Proton & Chemical shift in PPM & Proton group \\
\hline 6 & $1.22-1.24$ and $1.31-1.32$ & $-\mathrm{CH},-\mathrm{CH} 3$ \\
1 & 1.39 & $\mathrm{CH}$ \\
1 & 1.85 & $\mathrm{CH}$ \\
2 & 2.03 & $-\mathrm{CH} 2$ \\
2 & 2.51 & $-\mathrm{CH} 2$ \\
1 & 2.87 & $-\mathrm{CH}$ (Pyrol ring) \\
2 & 3.17 & $-\mathrm{CH} 2$ \\
2 & 4.51 & $-\mathrm{CH} 2$ \\
2 & $6.96-6.99$ & $\mathrm{Ar}-\mathrm{CH}$ \\
2 & $7.05,7.07$ & $\mathrm{Ar}-\mathrm{CH}$ \\
9 & $7.17-7.29$ & $\mathrm{Ar}-\mathrm{CH}$ \\
2 & $7.40-7.43$ & $\mathrm{Ar}-\mathrm{CH}$ \\
\hline
\end{tabular}

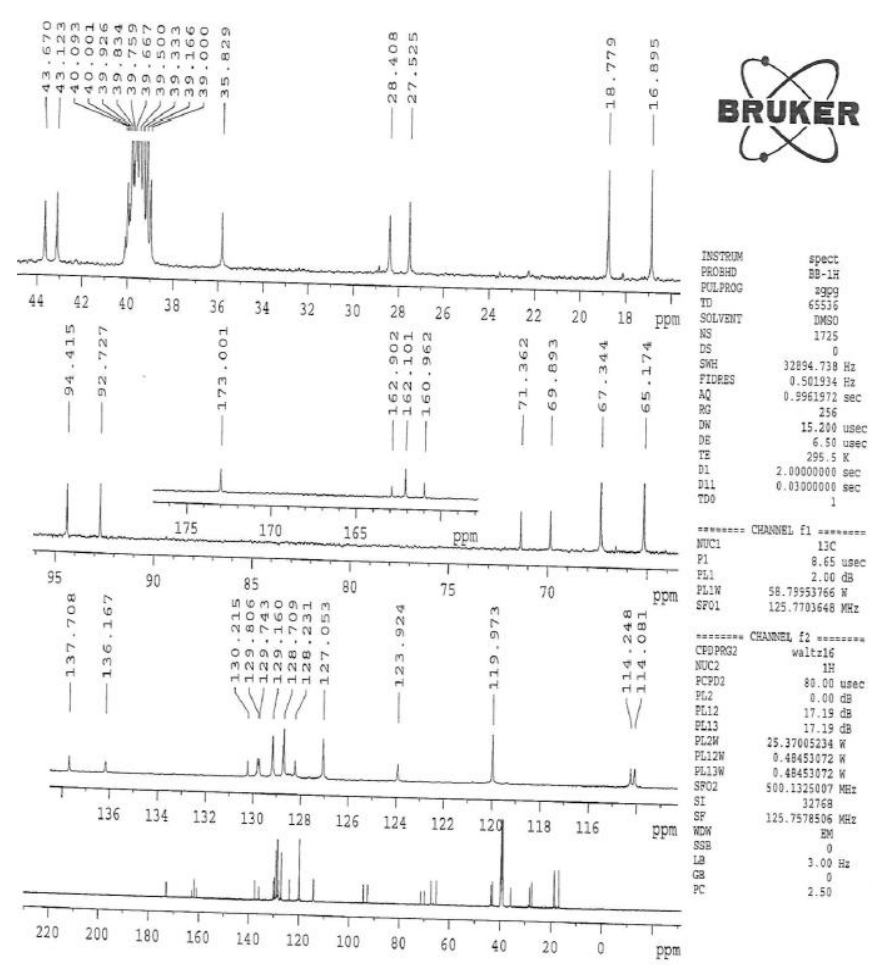

Fig. 10: ${ }^{13} \mathrm{C}$ NMR spectrum of unknown impurity

${ }^{13} \mathrm{C}$ NMR spectrum shows signals $68.990 \mathrm{ppm}, 72.298$ ppm, $93.174 \mathrm{ppm}$ and $94.758 \mathrm{ppm}$ corresponding to pyrrole C-5',C-4', C-3' and C-2' respectively in the ${ }^{13} \mathrm{C}$ NMR spectrum as shown below. This confirms the breakage of 5 membered pyrrole ring of atorvastatin leading to an upfield shift of these signals.

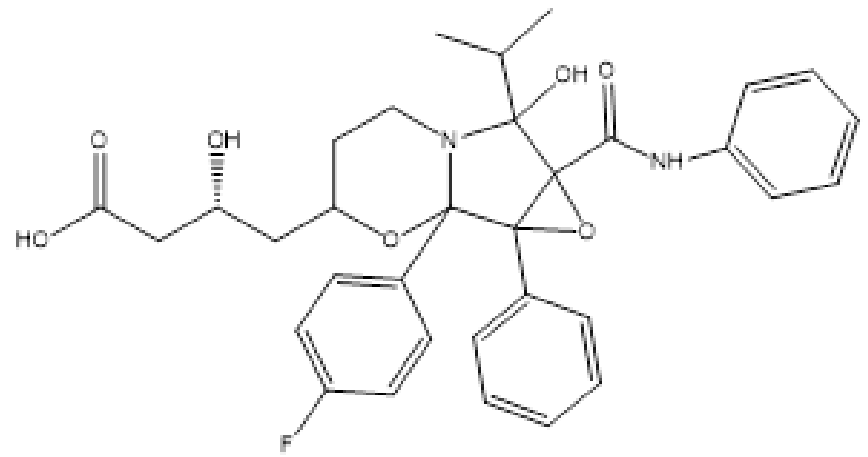

Fig. 11: Chemical structure of unknown impurity at RRT-1.84

\section{DISCUSSION}

Degradation condition for oxidative stress was optimized to enrich the unknown impurity at RRT-1.84 in Atorvastatin and Ezetimibe Tablets. Unknown degradation impurity is generating by oxidative degradation of Atorvastatin, which was identified by UV spectrum of the impurity and active drug. To isolate an unknown oxidative degradation impurity by preparative HPLC, the method was developed and the compound was isolated. The isolated impurity was analyzed by LCMS/MS with the mass compatible method. Based on the fragmentation pattern and probable degradation pattern shows two unstable structural isomeric compounds which is formed the cyclic analog of the Atorvastatin by the cyclization to the pyrrole ring. The isolated unknown impurity of atorvastatin was determined by quantitative NMR spectroscopy to be 4-[1b-(4-Fluoro-phenyl)-6-hydroxy6-isopropyl-1aphenyl-6a-phenylcarbamoyl-hexahydro1,2-dioxa-5a-aza-cyclopropa[a]inden-3-yl]-3-(R)-

hydroxy-butyric acid. The isolated, identified and characterized impurity was injected in the HPLC method and included in validation study to prove precision, linearity, the accuracy of the impurity in the developed method.

\section{REFERENCES}

1. Leiter LA, Bays H, Conard S, et al. Efficacy and Safety of Ezetimibe Added on to Atorvastatin $(40 \mathrm{mg})$ Compared With Uptitration of Atorvastatin (to $80 \mathrm{mg}$ ) in Hypercholesterolemic Patients at High Risk of Coronary Heart Disease. Am J Cardiol. 2008;102(11):1495-1501.

2. https://wenku.baidu.com/view/35a9708f9ec3d5bbfd0a74f3? pcf $=2 \&$ re $=$ view.

3. Filip K, Bańkowski K, Sidoryk K, et al. Physicochemical characterization of ezetimibe and its impurities. J Mol Struct. 2011; 991(1-3):162-170.

4. Kumar P, Ghosh A, Chaudhary M. Stability Indicating Method Development for Simultaneous Estimation of Ezetimibe and Atorvastatin in Pharmaceutical Formulations by RP-HPLC. Pharm Anal Acta. 2012;03(06):164.

5. Rajasekaran A, Sasikumar R, Dharuman J. Simultaneous RPHPLC method for the stress degradation studies of atorvastatin calcium and ezetimibe in multicomponent dosage form. Ars Pharm. 2011;52(3):12-18.

6. Yusuf SM, Samparna S, Yallareddy K, Pavani B, Sivakala T. Analytical method development and validation of atorvastatin and clopidogrel in tablet dosage form by RPHPLC. EJPMR 2017;4(4):553-558.

7. Kadav AA, Vora DN. Stability indicating UPLC method for simultaneous determination of atorvastatin, fenofibrate and their degradation products in tablets. J Pharm Biomed Anal. 2008;48(1):120-126.

8. Talluri MVNK, Kalyankar A, Ragampeta S. Synchronized separation of atorvastatin - an antihyperlipidemic drug with antihypertensive, antidiabetic, antithrombotic drugs by RPLC for determination in combined formulations. J Pharm Anal. 2012;2(4):285-292.

9. Suresh R, Manavalan R, Valliappan K. Developing and optimizing a validated RP-HPLC method for the analysis of amlodipine and ezetimibe with atorvastatin in pharmaceutical dosage forms applying response surface methodology. International Journal of Pharmacy and Pharmaceutical Sciences 2012; 4(3):550-558.

10. Londhe SV, Deshmukh RS, Mulgund SV, Jain KS Development and Validation of a Reversed-phase HPLC Method for Simultaneous Determination of Aspirin, 
Rajesh Desai et al. / Isolation, Identification and Characterization of Degradation Impurity of Atorvastatin.

Atorvastatin Calcium and Clopidogrel Bisulphate in Capsules. Indian J. Pharm. Sci., 2011;73(1):23-29.

11. Hafez HM, Elshanawany AA, Abdelaziz LM, Mohram MS. Development of a Stability-Indicating HPLC Method for Simultaneous Determination of Amlodipine Besylate and Atorvastatin Calcium in Bulk and Pharmaceutical Dosage Form. Pharm Anal Acta. 2014; 5(9):316.

12. https://sg.inflibnet.ac.in/bitstream/10603/27294/7/07_cha pter\%202.pdf.

13. Dubey S, Kumar Pandey R, Shankar Shukla S. Impurity Profiling and Drug Characterization: Backdrop and Approach. Indo Am. J P Sci. 2018;(04):2499-2515.

14. Nigovic B, Mornar A, Sertic M. A Review of Current Trends and Advances in Analytical Methods for Determination of Statins: Chromatography and Capillary Electrophoresis. In: Chromatography - The Most Versatile Method of Chemical Analysis. InTech; 2012.

15. Gupta LK. Spectroscopic characterization and quantitative determination of atorvastatin calcium impurities by novel
HPLC method. Spectrochim Acta Part A Mol Biomol Spectrosc. 2012; 97:495-501.

16. Ertürk S, Sevinç Aktaş E, Ersoy L, Fiçıcıoğlu S. An HPLC method for the determination of atorvastatin and its impurities in bulk drug and tablets. J Pharm Biomed Anal. 2003;33(5):1017-1023.

17. Sonje VM, Kumar L, Meena CL, et al. Atorvastatin Calcium Profiles Drug Subst Excipients Relat Methodol. 2010;35:1-70.

18. Kumar KK, Rao CK. A Validated Stability Indicating RPUPLC Method for Atrovastain Calcium. American Journal of Analytical Chemistry. 2012;3:392-399.

19. K. Gajjar A. Impurity Profiling: A Case Study of Ezetimibe. Open Conf Proc J. 2011;2(1):108-112.

20. Sistla R, Tata VSSK, Kashyap YV, Chandrasekar D, Diwan P V. Development and validation of a reversed-phase HPLC method for the determination of ezetimibe in pharmaceutical dosage forms. J Pharm Biomed Anal. 2005;39(3-4):517-522.

21. Gajjar AK, Shah VD. Isolation and structure elucidation of major alkaline degradant of Ezetimibe. J Pharm Biomed Anal. 2011;55(1):225-22.

HOW TO CITE THIS ARTICLE: Somwanshi SV, Thonte SS. Isolation, Identification and Characterization of Degradation Impurity of Atorvastatin in Fixed Dose Combination of Atorvastatin and Ezetimibe. Int. J. Pharm. Sci. Drug Res. 2019; 11(5): 187-193. DOI: 10.25004/IJPSDR.2019.110506 